\title{
An Analysis of Inpatient Pediatric Sickle Cell Disease: Incidence, Costs, and Outcomes
}

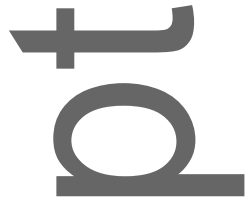

-

(2.
Laura M. Bou-Maroun, BS ${ }^{1}$

Fabien Meta, $\mathrm{BS}^{2}$

Curtis J. Hanba, MD ${ }^{2}$

Andrew D. Campbell, $\mathrm{MD}^{3,4}$

Gregory A. Yanik, $\mathrm{MD}^{4}$

${ }^{1}$ Department of Hematology - Central Michigan College of Medicine, Mt. Pleasant, Michigan, USA

${ }^{2}$ Department of Hematology - Wayne State University School of Medicine, Detroit, Michigan, USA

${ }^{3}$ Comprehensive Sickle Cell Program- University of Michigan Medical Center, Ann Arbor, Michigan, USA

${ }^{4}$ Division of Pediatric Hematology Oncology- University of Michigan Medical Center, Ann Arbor, Michigan, USA

Key Words: Sickle Cell Disease, Kids Inpatient Database, Acute Chest Syndrome, Vaso-

Occlusive Crisis, Cerebrovascular Accident, Splenic Sequestration, Hospitalization Costs

Running Title: Sickle Cell Admissions in Pediatric Patients

Financial Disclosures: None

Conflicts of Interest: None

Word Count Abstract: 250

Word Count Manuscript: 2605

\# of Tables, Figures, and Supplemental Files: 3 Tables, 2 Figures, No supplemental Files

Corresponding Author:

Laura M. Bou-Maroun, BS

Central Michigan University

College of Medicine

1280 East Campus Dr.

Mount Pleasant, MI 48859

Phone: $734-740-1555$

E-mail: bolma11m@cmich.edu

Manuscript Abbreviations Table:

SCD: Sickte Cell Disease

KID: Kids Inpatient Database

ACS: Acute Chest Syndrome

VOC: Vaso-occlusive Pain Crisis

CVA:Cerebrovascular Accidents

TIA: Transient Ischemic Attack

This is the author manuscript accepted for publication and has undergone full peer review but has not been through the copyediting, typesetting, pagination and proofreading process, which may lead to differences between this version and the Version of Record. Please cite this article as doi:

$10.1002 / \mathrm{pbc} .26758$.

This article is protected by copyright. All rights reserved. 
LOS: Length of Hospital Stay

$\mathrm{Hb}$ : Hemoglobin

ED: Emergency Department

TCD: Transcranial Doppler Ultrasonography

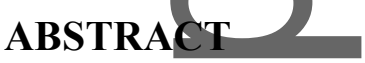

Objective:To identify characteristics of pediatric sickle cell disease (SCD) hospitalizations, and to examine admission demographics and medical expenditures.

Methods: Admissions with SCD were identified from the 2009 and 2012 releases of the Healthcare and Cost Utilization Project's Kids Inpatient Database. Disease-specific secondary diagnoses including; acute chest syndrome (ACS), vaso-occlusive pain crisis (VOC), splenic sequestration, and stroke/transient ischemic attack were analyzed for patient and hospital demographics. Analytical endpoints included total healthcare expenditures and mortality.

Results: We reviewed 75,234 inpatient hospitalizations with a diagnosis of SCD. Over $\$ 900,000,000$ was spent annually in associated healthcare expenditure. The median length of hospitalization stay (LOS) for-all admissions was 3 days (IQR 2-5 days). VOC was the most frequent secondary diagnosis, recording 48,698 total hospitalizations and a median LOS of 3 days (IQR 2-6 days). Of the 8,490 hospitalizations with ACS, the infant population had a significantly higher mortality rate compared to other age groups $(2 \%$ vs. $0.3 \%, \mathrm{p}<0.001)$. Cerebral vascular accidents incurred the second highest median hospitalization cost $(\$ 18,956)$, behind ACS $(\$ 22,631)$. A high proportion of Caucasian patients died during hospitalization for $\operatorname{VOC}(0.4 \%$ vs $0.1 \%, \mathrm{p}=0.014)$ and ACS $(4 \%$ vs $0.2 \%, \mathrm{p}<0.001)$ when compared to non-Caucasians.

Conclusion: Inpatient hospitalizations for secondary manifestations of pediatric SCD were associated with significant healthcare expenditures. Patients with an increased statistical risk for death during hospitalization included Caucasians with SCD complications of ACS and VOC, and patients $<1$-year-old with ACS. Further research is needed to substantiate the associated clinical significance of these findings.

Key Words: pediatric sickle cell disease, Kid's Inpatient Database, length of stay, hospitalization costs

This article is protected by copyright. All rights reserved. 


\section{INTRODUCTION}

Sickle cell disease (SCD) is an autosomal recessive genetic defect in hemoglobin ${ }^{1}$, with approximate incidences as high as 1 in 365 persons in the Black U.S. population. ${ }^{2}$ Disease manifestations can include pain crisis, splenic sequestration, acute chest syndrome (ACS), and cerebrovascular accidents (CVA). These conditions are largely the result of a mechanistically similar vaso-occlusive phenomena, ${ }^{1,3}$ yet the morbidity, mortality, and healthcare expenditure associated with each presentation differs greatly. The National Institutes of Health has dedicated over one quarter of a billion dollars in recent years (2007-2013) to basic science and clinical research efforts targeting treatment and prevention modalities within this disorder. ${ }^{4}$

In 2010, Brousseau and colleagues reported sickle cell vaso-occlusive crisis (VOC) was the leading cause of hospital utilization for SCD patients. ${ }^{5}$ They found demographic and socioeconomic factors including age and insurance payer type to modify one's frequency of hospitalization and incidence of 30 day rehospitalization. Two related publications reported similar trends in hospitalization and incidence. ${ }^{6,7}$ Despite significant scientific inquiry into SCD incidence and associated healthcare expenditures, there remains a lack of population based investigation into factors contributing to one's length of hospitalization stay (LOS), and outcome analysis, including death.

The population-based, database approach we have employed affords statistical power in analyzing SCD hospitalizations in low incidence groups, as well as providing better aggregate perspectives to already well-studied populations. In the United States, progressive social advancements and generations of immigration have created a vibrant, melting-pot population. With this comes a variety of genetic diseases that are being seen in a more diverse group of patients. In Europe, immigration en masse is a more recent phenomenon than in the U.S. and its effects are already being seen in hemoglobinopathies and SCD epidemiology. ${ }^{8,9}$ As a result, reporting on traditionally understudied groups has added utility in the modern world. Although not often reported in the U.S., A New York newborn screening program estimates Caucasian (non-Hispanic) SCD incidences as low as 1: 40,000 births. ${ }^{10}$ Large patient sample sizes possible through large databases are required for adequate power to analyze these hospitalizations. . 
Our analysis aimed to identify populations with high risk complications and the expenditures associated with those complications. Furthermore, our analysis of admissions with SCD stands to not only direct therapy in communities with heavy disease burden, such as Black and Hispanic American communities, but also shed light on populations with lower incidences of SCD that are not typically studied. METHODS

We reviewed inpatient records from 2009 and 2012 of the Kids Inpatient Database (KID). ${ }^{11}$ The KID is maintained by the Agency for Healthcare Research and Quality's Healthcare Cost and Utilization Project, and contains information about patient and hospital characteristics for roughly $80 \%$ of hospitalizations for children $(<21$ years $)$ in the United States. The database includes admissions from approximately 4,100 U.S. hospitals in 44 of the 50 states. Historically new releases of the KID have occurred every 3 years, with versions of the KID prior to 2016 used ICD-9 coding, while subsequent versions used ICD-10. Our study, utilizing the 2009 and 2012 databases represents a comprehensive analysis with one coding scheme (ICD-9). Several recent publications have used the KID in a similar manner to characterize other pediatric conditions. ${ }^{12-14}$

Admissions with SCD were identified within the KID by queries of ICD-9 diagnosis codes 282.62 (Hb-SS Disease with crisis), 282.61 (Hb-SS Disease without crisis) and 282.60 (Sickle Cell Anemia NOS). Admissions with potential disease-specific SCD diagnoses (ACS, VOC, CVA, splenic sequestration) were identified by ICD-9 codes, with patient demographic and hospitalization characteristics characterized. Admission sample weights provided by the KID were used to adjust the roughly $80 \%$ cohort of American hospitalizations into a validated nationwide estimation. Endpoints included patient age, race, gender, billable charges excluding physician fees, death, and length of hospitalization (LOS). Charges from 2009 were adjusted for inflation by utilizing US Department of Commerce Bureau of Economic Analysis website coefficients to match 2012 costs. Our study qualified as non-identifiable human subject research employing the use of publicly available data, and thus was exempted from IRB approval.

\section{Statistical Analysis}

This article is protected by copyright. All rights reserved. 
Data were grouped for analysis using SPSS statistical software version 23 (Armonk, NY: IBM Corp) and Microsoft Excel (Seattle, WA). Medians and interquartile ranges (IQR) were used to describe the distribution of data for LOS and charges per admission. A multivariate binary logistic regression analysis was conducted to explore independent predictors contributing to mortality (mortality vs. no mortality) during SCD hospitalization. ANOVA analyses were run to compare continuous samples where applicable, with a threshold for statistical significance set at $\mathrm{p}<0.05$. RESULTS

A total of 75,234 hospitalizations reporting a diagnosis of SCD were collectively reported in 2009 and 2012 (Table 1). Of these hospitalizations, $70.1 \%$ and $87.3 \%$ were from urban teaching hospitals in 2009 and 2012, respectively_with approximately only 3.5\% from rural hospitals during each of the two years. Annual healthcare expenditure for SCD admissions totaled over $\$ 900,000,000$, with a median hospitalization cost of $\$ 14,337$ per stay. Black patients accounted for a majority of admissions (81.6\%) with Hispanics (4.6\%) and Caucasians (1.6\%.) totaling substantially smaller cohorts. Individuals between $16-20$ years old accounted for $38.4 \%$ of hospitalizations for SCD.

The overall mortality associated with any inpatient hospitalization was $0.1 \%$. Multi-variate analysis (Table 2) demonstrated that a diagnosis of congenital heart disease $(p<0.001)$, sepsis $(p<$ $0.001)$, stroke ( $\mathrm{p}<0.001)$, and ACS $(\mathrm{p}<0.001)$ all carried statistical predilection for increased risk of patient death during these pediatric hospitalizations.

\section{Acute Chest Syndrome}

Overall,there were 8,490 hospitalizations recording a diagnosis of acute chest syndrome (ACS) (Table 1). The median length of hospitalization in this cohort was 4 days (IQR range 3-7 days), with median hospitalization charges $\$ 22,631$ per admission. Figures 1a and $\mathbf{1 b}$ depict incidence and length of stay by age grouping respectively. Twenty-five patients (0.3\%) admitted with ACS died during their hospitalization. Table 3 details rates of mortality in ACS; as displayed, patients $<1$-year-old had a statistically significant higher risk of death $(\mathrm{p}<0.001)$. Also, a statistically significant greater proportion of Caucasian patients (3.8\%) died during hospitalization when compared to mortality from 
SCD in other racial and ethnic groups ( $\mathrm{p}<0.001)$. Collectively, hospitalizations for ACS averaged $\$ 24,115,994$ in annual expenditures.

Vaso-Occlusive Crisis

VOC accounted for 48,698 hospitalizations, the highest subtotal over the two-year period of study

(Table 1), with nearly half (47.6\%) of the hospitalizations in patients aged 16-20 years (Figure 1c).

Caucasian admissions contributed to only $1.4 \%$ of the VOC cohort, however these patients carried a statistically significant increased risk of death during their hospitalization, $(0.4 \%, p=0.020)$ (Table 3). In all, 47 patients $(0.1 \%)$ with a diagnosed VOC died during their inpatient stay. Collectively, hospitalizations for vaso-occlusive crises averaged $\$ 189,863,407$ in annual expenditures.

Splenic Sequestration

Splenic Sequestration was most commonly identified in admissions of patients $<5$ years in age (72.4\%) (Table 1)(Figure 2a). Length of stay trended towards longer hospitalizations as age increased (Figure 2b). Death was an uncommon occurrence, and was witnessed in $<0.1 \%$ of hospitalizations for splenic sequestration. Collectively, hospitalizations for splenic sequestration averaged $\$ 6,621,818$ in annual expenditures.

Cerebrovascular Accident

In total, 3,669 cerebrovascular events occurred during SCD hospitalizations (Table 1). Incidence increased with age (Figure 2c). A graph identifying median length of stay by age group revealed longer hospitalizations for older patients as well. (Figure 2d). No age cohort carried a statistically significant predilection for death following a cerebrovascular event (Table 3). Overall, 20 patients $(0.5 \%)$ died during an admission associated with a CVA or TIA. Collectively, hospitalizations for The

CVA in pediatric SCD totaled $\$ 11,592,354$ in expenditures yearly.

\section{DISCUSSION}

Investigation of the cost, length of stay, and mortality of SCD hospitalizations and its complications can provide useful context to clinical presentation. As with other database studies, our results rely on the accuracy of medical chart reporting of demographics, an important caveat that is discussed further in the limitations. Despite that, our study encompasses one of the largest current 
collections of SCD patients and enables adequate power for analysis of understudied patient populations. We found that Caucasian patients had increased rates of mortality during hospitalizations for ACS or-VOC. Despite widespread newborn screening in the U.S., ${ }^{15}$ SCD may be under recognized in the non-Black population, especially if patients have immigrated to the U.S. after the newborn period. From a practical standpoint, the absolute mortality $(n=4)$ in the Caucasian SCD demographic limited any definitive clinical conclusions. Finally, we must consider that the KID may have inaccurately categorized patients by racial or ethnic group, especially in situations involving biracial children. Further study of SCD-related mortality in non-Black populations may help substantiate these findings.

With regards to ACS, the significantly higher mortality we report in infant admissions may be due to the relatively non-specific criteria for ACS (fever, increased work of breathing, new infiltrate on chest x-ray, decline of respiratory status, etc.). This may lead to under recognition, and misdiagnosis of ACS for less severe clinical entities such as pneumonia or bronchiolitis. A recent report proposes that monitoring the rate of respiratory decline can help ensure a more accurate diagnosis of ACS. ${ }^{16}$ Heightened vigitance and the refinement of ACS diagnostic criteria may curtail mortality in this this high-risk age group.

VOC hospitalizations accounted for over half of the total hospitalizations, and were more common in older pediatric age groups. These findings support a similar analysis of KID data from 1997 where LOS also increased with age. ${ }^{7}$ This highlights an ever-present clinical scenario suggesting that age may be a reliable predictor of a patient's LOS or episodic severity. We suspect that recognition of this clinical trend may allow for streamlining measures to decrease hospital expenditure and patient suffering by encouraging early and adequate pain management strategies. However, it seems that the unfortunate incorporeal nature of an individual's pain, in combination with recent initiatives to decrease opioid medication use may still leave practitioners hesitant to adequately manage a patient's VOC pain erisis. Emergency department (ED) providers may have a bias towards pain medication addiction when it comes to sickle cell related pain. ${ }^{17}$ African-Americans with SCD have been shown to have $25 \%$ longer ED wait times compared to other patient populations, suggesting that racial 
disparities may impact time to medical care. ${ }^{18}$ Nonetheless, this hesitancy towards swift care and analgesia in the ED might allow pain crises to advance to levels more difficult to manage, further increasing LOS and costs.

In line with prior literature, we found that patients admitted for splenic sequestration most commonly were within the youngest population of patients analyzed (0-5 years). In a cohort of 190 patients with SCD diagnosed at birth, the median age of the first episode of acute splenic sequestration crisis occurred at 1.4 years. ${ }^{19}$ Moreover, these same patients experienced 437 episodes of splenic sequestration collectively with $67 \%$ of these patients experiencing more than one episode. ${ }^{19}$ In our analysis, the incidence of splenic sequestration hospitalizations also decreased as patients grew older. This is likely explained by the notion that the probability of sequestration decreases as the amount of functional splenic tissue decreases in older patients through repeated tissue infarctions. Up to $90 \%$ of SCD patients aged 5 years old have functional or anatomical asplenia. ${ }^{20}$ Also noteworthy, patient mortality from splenic sequestration was low $(<0.1 \%)$ in our sample. However, older reports from a sickle cell cohort study with 216 patients from 1981 had mortality rates as high as $12 \%$ within the first episode. 21 The decline we see in mortality rates between our data and older reports over the last 35 years may be due to implementation of more widespread newborn screening, patient education, transfusion programs and prophylactic splenectomies. ${ }^{22}$

The mortality rate for CVA was the highest of the four diagnoses, while median costs ranked second highest. This result illustrates the clinical and economic impact that a stroke diagnosis carries in patients with SCD. For such reasons, primary stroke prevention strategies have been becoming more popular. A recent systematic review and cost-effectiveness analysis concluded that use of transcranialdoppler (TCD) ultrasonography for identifying children with high risk for stroke and prophylactic blood transfusions appeared to be both clinically effective and cost-effective when compared to sereening with TCD ultrasonography alone. ${ }^{23}$ Other studies have shown that hydroxyurea therapy is another cost-effective option for secondary stroke prevention in children with SCD, especially in resource constrained countries. ${ }^{24}$ Newer investigations from the TWiTCH trial have 
shown that hydroxyurea therapy can decrease TCD velocities, which may be an indicator of reduced stroke risk in pediatric SCD patients. ${ }^{25}$

Such innovative prevention strategies are starting to change the age distribution of stroke diagnosis in patients with SCD. When looking at a pediatric subset (ages 0-20) from a prospective, multi-center study which enrolled 4082 patients from the years 1978 to 1988, there was a peak incidence of stroke between ages of 2-9. ${ }^{26}$ However, our data shows that SCD hospitalizations with stroke was far more common in the 10-20 age range, with a peak in the 19-year-old age group. We hypothesize that such a shift in age preference during the last few decades could largely be a result of prevention strategies and close monitoring earlier in a patient's life. However, as a patient ages, the financial burden and time-commitment required to manage SCD becomes sizeable. These patients may be lost to follow up, rendering prevention strategies difficult to implement, effectively delaying CVA incidence rather than reducing it. The time-intensive nature of SCD in children is highlighted by reports that claim these students miss up to $10 \%$ of the average school year. ${ }^{27}$ Thus, there may be a necessity to implement programs to help alleviate the inconveniences that are associated with frequent sickle cell care (e.g. driving tong distances to hospitals with sickle cell programs). While some effective programs already exist, ${ }^{28}$ more focus on this matter may help recapture patients lost to follow up for these reasons.

Although our study encompasses one of the largest cohorts of pediatric SCD hospitalizations available and identifies key demographical discrepancies of care, the resources incorporated into our analysis carry a few important limitations worthy of remark. Primarily, KID data uses hospital discharge paperwork, and relies on the accuracy of reported admission characteristics. Specifically, patient race is a difficult analysis to validate from hospital level discharge as patient demographics may not be self-reported. ${ }^{29,30}$ Yet, the more often a patient presents to a healthcare system (e.g. hospitalizations), there is greater agreement between patient self-reported race/ethnicity data and administrative recording of race/ethnicity (e.g. medical chart data). ${ }^{29}$ In other words, there are more opportunities to record accurate demographic data. From this we can reasonably surmise that the SCD admission demographics from the KID database, are more likely to be accurate since SCD patients 
frequently visit healthcare systems (e.g. emergency department visits, hospitalizations, etc.). ${ }^{31}$

Secondly, databases such as the KID contain only admission-level data and frequently do not provide information about treatment modalities or patient history for context. Therefore, this impacts the applicability of some of our findings. Finally, without patient identifiers to examine one's severity of disease it becomes difficult to identify whether a small subset of patient's greatly impacts expenditure and resource utilization in SCD. However, by including over 70,000 hospitalizations, from over 4,000 hospitals nationwide, the quantity of data analyzed provides an aggregate hospitalization depiction that still provides utility from an epidemiological perspective. Typically, large database studies such as this offer a broad complement to more clinically focused intra-institutional studies where casespecific data is more robust, but likely underpowered.

In conclusion, the data presented here highlights pediatric SCD mortality and related patient demographics. Additionally, SCD and its common complications are associated with considerable aggregate and admission-level expenditures. Hospitalizations with ACS and VOC in Caucasian populations are associated with statistically significant higher mortality rates, as are infants with ACS. Further studies may more closely characterize these discrepancies.

\section{References}

1. Bunn HF, Aster J. Pathophysiology of blood disorders. New York: McGraw-Hill; 2011.

2. CDC. Sickle Cell Disease Data \& Statistics. http://www.cdc.gov/ncbddd/sicklecell/data.html. Accessed August 10, 2016.

3. Hoppe CC. Newborn screening for hemoglobin disorders. Hemoglobin. 2011;35(5-6):556-

$$
564 .
$$

4. Gavini N, Hoots WK, Mensah GA, Hanspal M. An analysis of the NIH-supported sickle cell disease research portfolio. Blood Cells Mol Dis. 2015;54(2):198-205.

5. BrousseaU DC, Owens PL, Mosso AL, Panepinto JA, Steiner CA. Acute care utilization and rehospitalizations for sickle cell disease. JAMA. 2010;303(13):1288-1294.

6. Ellison AM, Bauchner H. Socioeconomic status and length of hospital stay in children with vaso-occlusive crises of sickle cell disease. J Natl Med Assoc. 2007;99(3):192-196. 
7. Panepinto JA, Brousseau DC, Hillery CA, Scott JP. Variation in hospitalizations and hospital length of stay in children with vaso-occlusive crises in sickle cell disease. Pediatr Blood Cancer. 2005;44(2):182-186.

8. Modell B, Darlison M, Birgens H, et al. Epidemiology of haemoglobin disorders in Europe:

an overview. Scand J Clin Lab Invest. 2007;67(1):39-69.

9. Roberts I, de Montalembert M. Sickle cell disease as a paradigm of immigration hematology: new challenges for hematologists in Europe. Haematologica. 2007;92(7):865-871.

10. Wang Y,Kennedy J, Caggana M, et al. Sickle cell disease incidence among newborns in New York State by maternal race/ethnicity and nativity. Genet Med. 2013;15(3):222-228.

11. AHRQ. HCUP Databases: KID Overview. 2016; https://www.hcupus.ahngrow/kidoverview.jsp. Accessed October 6, 2016.

12. Bekelis K, Connolly ID, Do HM, Choudhri O. Operative volume and outcomes of cerebrovascular neurosurgery in children. J Neurosurg Pediatr. 2016;18(5):623-628.

13. Hanba C, Bobian M, Svider PF, et al. Perioperative considerations and complications in pediatrie parathyroidectomy. Int J Pediatr Otorhinolaryngol. 2016;91:94-99.

14. Hanba C, Svider PF, Shkoukani MA, et al. Pediatric pituitary resection: characterizing surgical approaches and complications. Int Forum Allergy Rhinol. 2016.

15. Benson JM, Therrell BL, Jr. History and current status of newborn screening for hemoglobinopathies. Semin Perinatol. 2010;34(2):134-144.

16. DeBaun MR, Strunk RC. The intersection between asthma and acute chest syndrome in children with sickle-cell anaemia. Lancet. 2016;387(10037):2545-2553.

17. Shapiro BS, Benjamin LJ, Payne R, Heidrich G. Sickle cell-related pain: perceptions of medical practitioners. J Pain Symptom Manage. 1997;14(3):168-174.

18. Haywood C, Jr., Tanabe P, Naik R, Beach MC, Lanzkron S. The impact of race and disease on sickle cell patient wait times in the emergency department. Am J Emerg Med. 2013;31(4):651-656. 
19. Brousse V, Elie C, Benkerrou M, et al. Acute splenic sequestration crisis in sickle cell disease: cohort study of 190 paediatric patients. Br J Haematol. 2012;156(5):643-648.

20. Brown AK, Sleeper LA, Miller ST, Pegelow CH, Gill FM, Waclawiw MA. Reference values and hematologic changes from birth to 5 years in patients with sickle cell disease.

Cooperative Study of Sickle Cell Disease. Arch Pediatr Adolesc Med. 1994;148(8):796-804.

21. Topley JM, Rogers DW, Stevens MC, Serjeant GR. Acute splenic sequestration and hypersplenism in the first five years in homozygous sickle cell disease. Arch Dis Child. 1981:56(10):765-769.

22. Owust-Ofori S, Remmington T. Splenectomy versus conservative management for acute sequestration crises in people with sickle cell disease. Cochrane Database Syst Rev.

2015(9):CD003425.

23. Cherry MG, Greenhalgh J, Osipenko L, et al. The clinical effectiveness and cost-effectiveness of primary stroke prevention in children with sickle cell disease: a systematic review and economic evaluation. Health Technol Assess. 2012;16(43):1-129.

24. Cunningham-Myrie C, Abdulkadri A, Waugh A, et al. Hydroxyurea use in prevention of stroke recurrence in children with sickle cell disease in a developing country: A cost effectiveness analysis. Pediatr Blood Cancer. 2015;62(10):1862-1864.

25. Ware RE, Davis BR, Schultz WH, et al. Hydroxycarbamide versus chronic transfusion for maintenance of transcranial doppler flow velocities in children with sickle cell anaemia-TCD With Transfusions Changing to Hydroxyurea (TWiTCH): a multicentre, open-label, phase 3, non-inferiority trial. Lancet. 2016;387(10019):661-670.

26. Ohene-Frempong K, Weiner SJ, Sleeper LA, et al. Cerebrovascular accidents in sickle cell disease: rates and risk factors. Blood. 1998;91(1):288-294.

27. Schatz J. Brief report: Academic attainment in children with sickle cell disease. J Pediatr Psychol. 2004;29(8):627-633. 
28. Smeltzer MP, Nolan VG, Yu X, et al. Distance from an Urban Sickle Cell Center and its Effects on Routine Healthcare Management and Rates of Hospitalization. Hemoglobin. 2016;40(1):10-15.

29. Kressin NR, Chang BH, Hendricks A, Kazis LE. Agreement between administrative data and patients' self-reports of race/ethnicity. Am J Public Health. 2003;93(10):1734-1739.

30. Zingmond DS, Parikh P, Louie R, et al. Improving Hospital Reporting of Patient Race and Ethnicity--Approaches to Data Auditing. Health Serv Res. 2015;50 Suppl 1:1372-1389.

31. Wolfson JA, Schrager SM, Coates TD, Kipke MD. Sickle-cell disease in California: a population-based description of emergency department utilization. Pediatr Blood Cancer.

2011;56(3):413-419.

\section{FIGURE LEGENDS}

A 3000

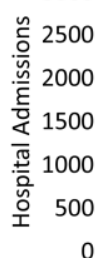

C

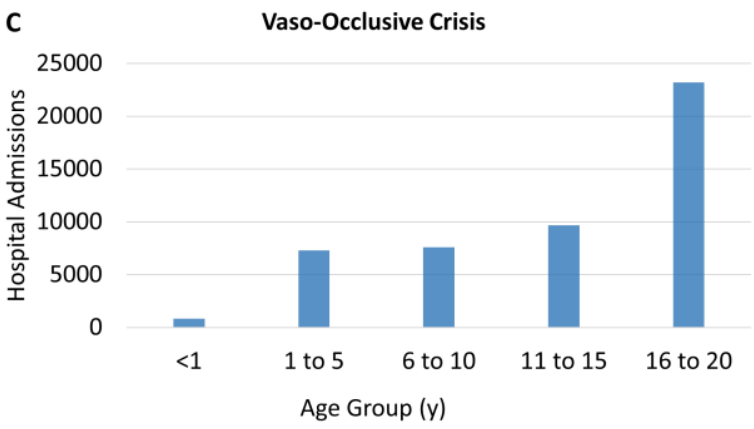

Acute Chest Syndrome

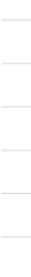

$<1$

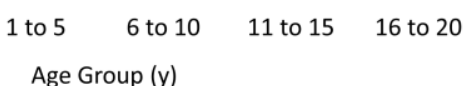

Age Group (y)

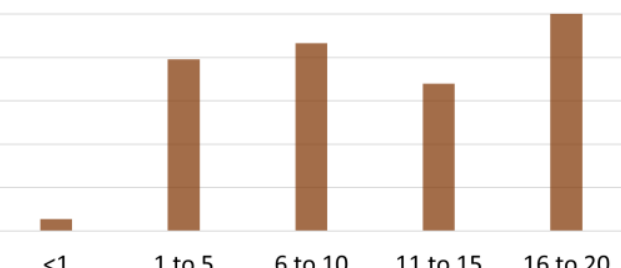

)

Figure 1 A-D Acute Chest Syndrome (ACS) (A, B) and Vaso-Occlusive Crisis (C, D): Total number of hospitalizations stratified by age group (A, C) and Median Length of Inpatient Admission (LOS) (B, D) by Age Group.
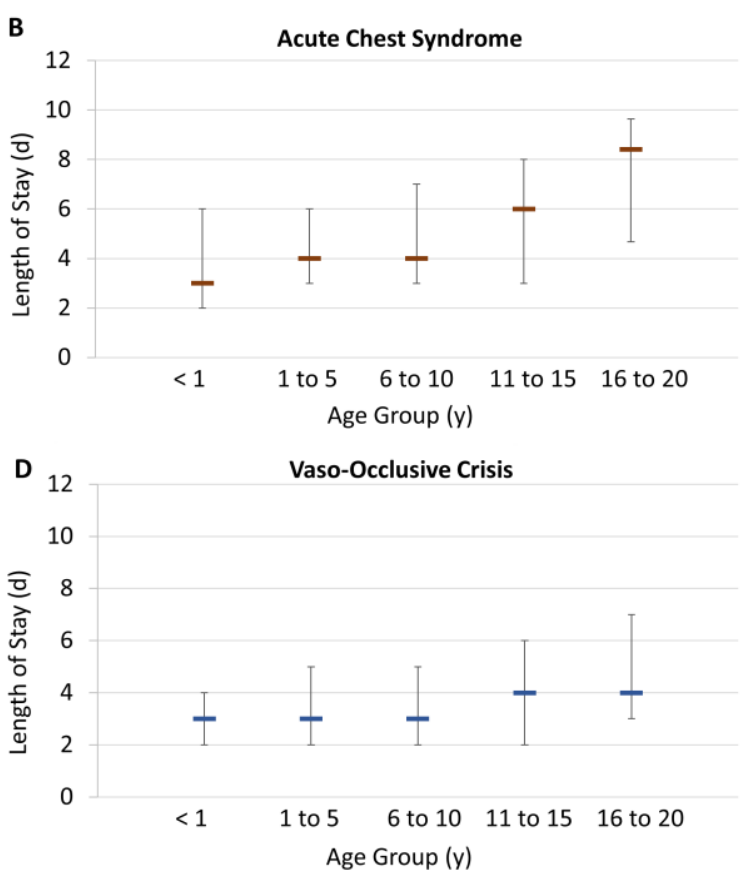

This article is protected by copyright. All rights reserved. 

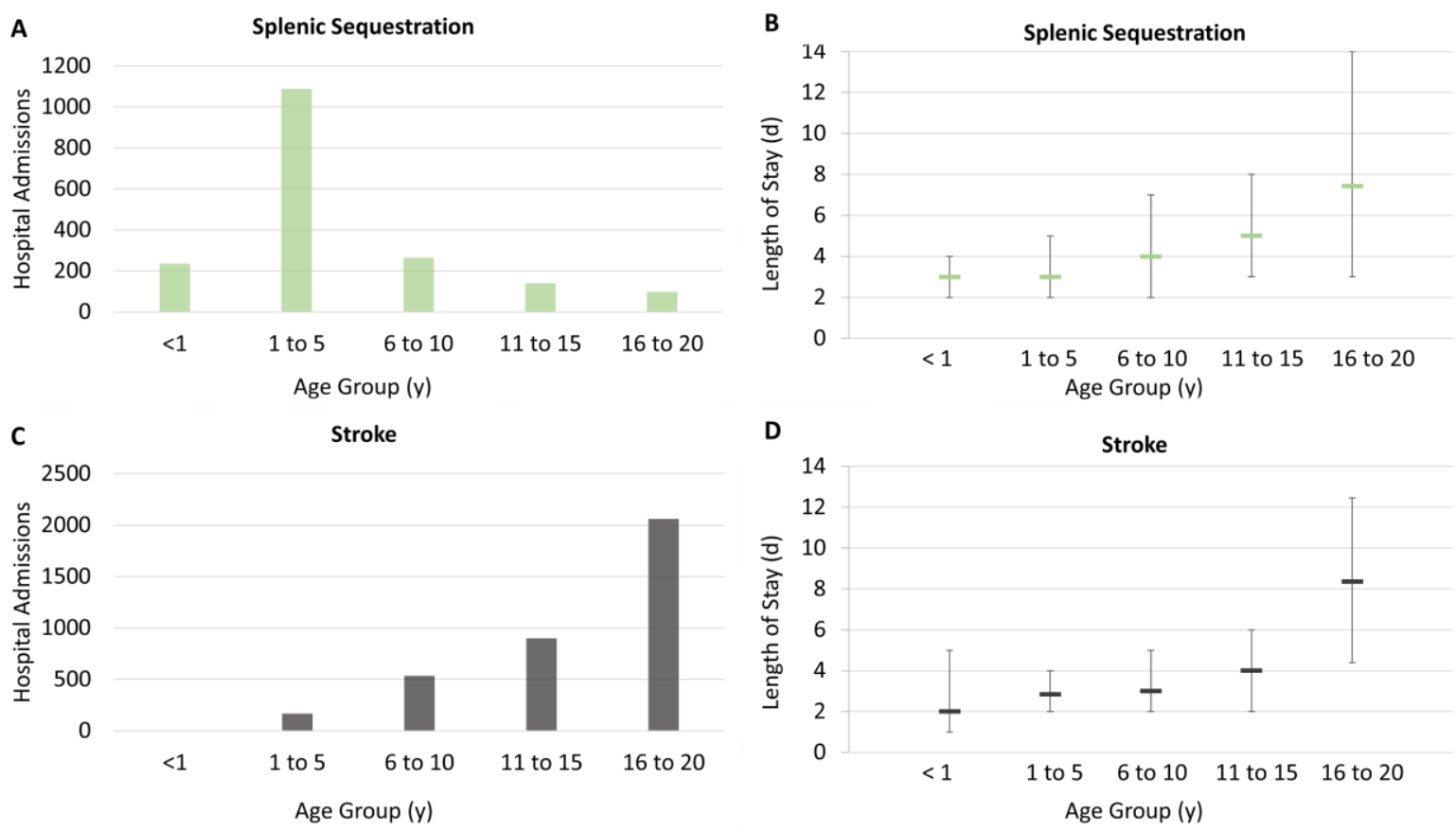

Figure 2 A-D Splenic Sequestration (Splenic) (A, B) and Stroke (C, D): Total number of hospitalizations stratified by age group (A, C) and Median Length of Stay (LOS) (B, D) by Age Group.

Table 1: Database Characteristics

\begin{tabular}{|c|c|c|c|c|c|}
\hline & issions & ACS (\%) & $\begin{array}{l}\text { Vaso- } \\
\text { Occlusive } \\
(\%)\end{array}$ & Splenic (\%) & Stroke (\%) \\
\hline No. & 75,234 & 8,490 & 48,698 & 1,881 & 3,669 \\
\hline \multicolumn{6}{|l|}{ Ages } \\
\hline$<1$ & $4,022(5.3)$ & $137(1.6)$ & $830(1.7)$ & 237 (12.9) & --- \\
\hline $1-5$ & $\begin{array}{l}15,957 \\
(21.2)\end{array}$ & $\begin{array}{l}1,978 \\
(23.3)\end{array}$ & $\begin{array}{l}7,312 \\
(15.0)\end{array}$ & $\begin{array}{l}1,089 \\
(59.5)\end{array}$ & $197(4.6)$ \\
\hline $6-10$ & & $\begin{array}{l}2,165 \\
(25.5)\end{array}$ & $\begin{array}{l}7,595 \\
(15.6)\end{array}$ & 265 (14.5) & $534(14.5)$ \\
\hline $11-15$ & $\begin{array}{l}13,925 \\
(18.5)\end{array}$ & $\begin{array}{l}1,698 \\
(20.2)\end{array}$ & $\begin{array}{l}9,684 \\
(19.9)\end{array}$ & $139(7.6)$ & $898(24.5)$ \\
\hline $16-20$ & $\begin{array}{l}28,897 \\
(38.4)\end{array}$ & $\begin{array}{l}2,505 \\
(29.5)\end{array}$ & $\begin{array}{l}23,193 \\
(47.6)\end{array}$ & $98(5.3)$ & $2060(56.1)$ \\
\hline $\mathrm{O} / \mathrm{NR}$ & $112(0.1)$ & --- & $84(0.2)$ & --- & --- \\
\hline
\end{tabular}

This article is protected by copyright. All rights reserved. 


\begin{tabular}{|c|c|c|c|c|c|}
\hline Sex & & & & & \\
\hline Male & 37,661 & $\begin{array}{l}4,754 \\
(56.0)\end{array}$ & $\begin{array}{l}24,033 \\
(49.4)\end{array}$ & 996 (54.4) & $1813(49.4)$ \\
\hline Female & & $\begin{array}{l}3,729 \\
(43.9)\end{array}$ & $\begin{array}{l}24,585 \\
(50.5)\end{array}$ & $839(45.6)$ & 1856 (50.6) \\
\hline Race & & & & & \\
\hline Caucasian & (1.6) & 107 (1.3) & 664 (1.4) & $36(2.0)$ & $31(0.9)$ \\
\hline Black & & $\begin{array}{l}6,843 \\
(80.6)\end{array}$ & $\begin{array}{l}40,614 \\
(83.4)\end{array}$ & $\begin{array}{l}1,370 \\
(74.8)\end{array}$ & 3012 (82.1) \\
\hline Hispanic & (4.6) & 400 (4.7) & 2,091 (4.3) & $150(8.2)$ & 181 (4.9) \\
\hline Asian & $177(0.2)$ & $32(0.4)$ & $103(0.2)$ & $11(0.6)$ & $10(0.3)$ \\
\hline $\mathrm{O} / \mathrm{NR}$ & & $\begin{array}{l}1,108 \\
(13.1)\end{array}$ & $\begin{array}{l}5,225 \\
(10.7)\end{array}$ & $263(14.4)$ & $434(11.8)$ \\
\hline LOS (IQR) & & $4(3-7)$ & $3(2-6)$ & $3(2-4)$ & $3(2-6)$ \\
\hline $\begin{array}{l}\text { Charges } \\
\text { (\$) }\end{array}$ & & 22,631 & 15,566 & 14,858 & 18,956 \\
\hline (IQR) & & $\begin{array}{l}(13,314- \\
41,190)\end{array}$ & $\begin{array}{l}(9,139- \\
27,726)\end{array}$ & $\begin{array}{l}(9,065- \\
27,098)\end{array}$ & $\begin{array}{l}(10,785- \\
35,100)\end{array}$ \\
\hline Death & $91(0.1)$ & $25(0.3)$ & $47(0.1)$ & --- & $20(0.5)$ \\
\hline
\end{tabular}

ACS - Acute chest syndrome, Splenic - Splenic sequestration, Stroke - Stroke/TIA, O/NR - other/not recorded during hospitalization, LOS - Length of hospitalization (days), IQR - Interquartile Range, --too few patients to report national incidence estimation, LOS and Charges reported as median with IQR

Table 2: Multivariate Analysis: Mortality by Diagnosis/Characteristic Regression Outputs

\begin{tabular}{|l|l|l|l|}
\hline & Odds Ratio & $\begin{array}{l}95 \% \text { Cl for Odds } \\
\text { Ratio }\end{array}$ & Sig. \\
\hline SCD Related & & & \\
\hline Sepsis & 44.6 & $28.8-69.2$ & $<0.001$ \\
\hline CVA & 3.7 & $2.2-6.3$ & $<0.001$ \\
\hline
\end{tabular}

This article is protected by copyright. All rights reserved. 


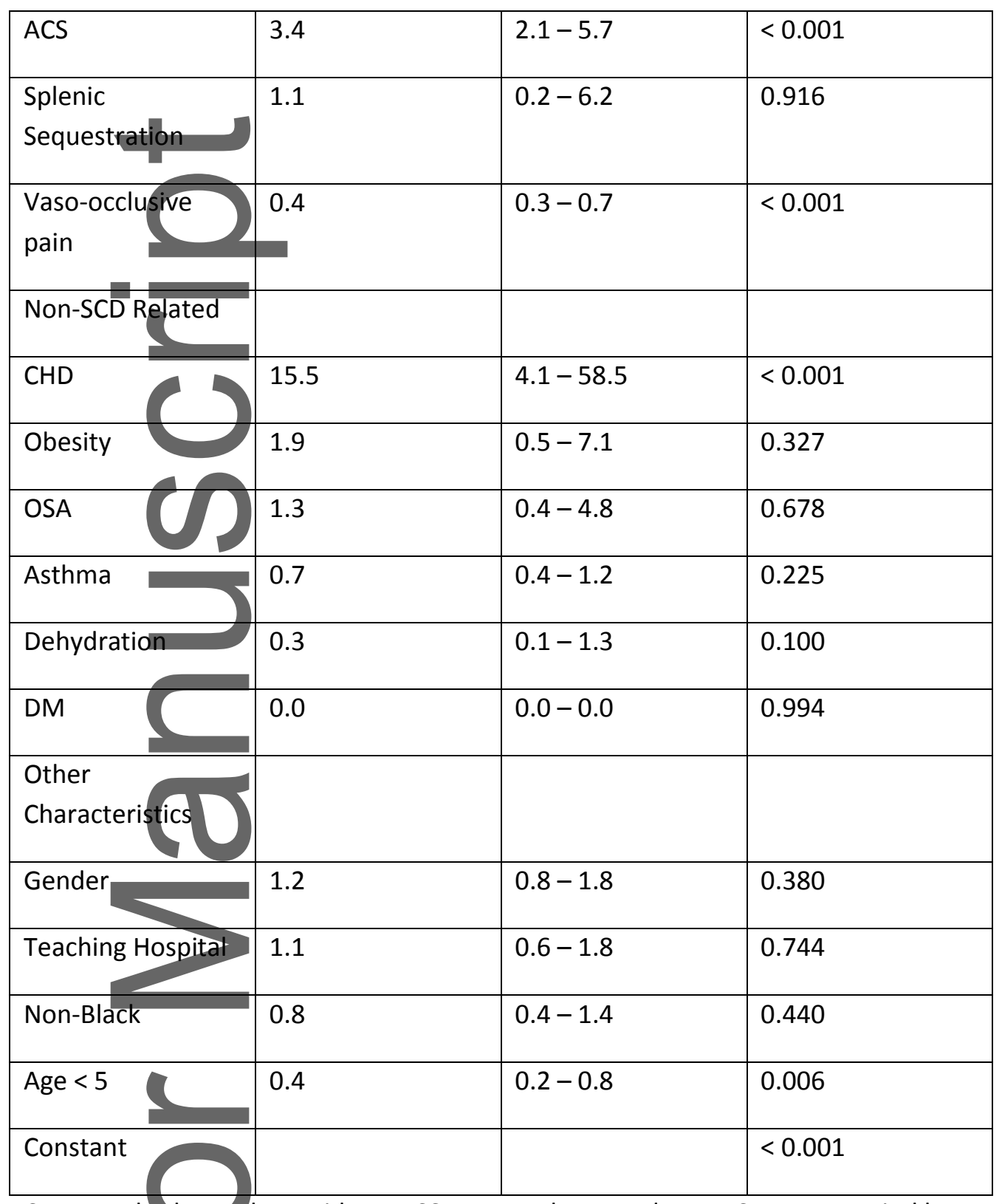

$\mathrm{CVA}=$ cerebrat vascular accident, $\mathrm{ACS}=$ acute chest syndrome, $\mathrm{CHD}=$ congenital heart disease OSA = obstructive sleep apnea, DM = diabetes mellitus, Odds Ratio reflects death incidence in conjunction with comorbid diagnosis, Gender represents male sex

Table 3:2009 and 2012 Inpatient Mortality

\begin{tabular}{|l|l|l|l|}
\hline & ACS & Vaso-Occlusive & Stroke/TIA \\
\hline $\mathrm{N}$ & 25 & 47 & 20 \\
\hline Ages & & & \\
\hline$<1$ & $2.0 \%^{\mathrm{p}<0.001}$ & $0.0 \%^{\mathrm{p}=0.233}$ & $0.0 \%^{\mathrm{p}=0.907}$ \\
\hline $1-5$ & $0.0 \%$ & $<0.1 \%$ & $0.9 \%$ \\
\hline
\end{tabular}

This article is protected by copyright. All rights reserved. 


\begin{tabular}{|l|l|l|l|}
\hline $6-10$ & $0.4 \%$ & $0.1 \%$ & $0.3 \%$ \\
\hline $11-15$ & $0.1 \%$ & $0.1 \%$ & $0.7 \%$ \\
\hline $16-20$ & $0.5 \%$ & $0.1 \%$ & $0.5 \%$ \\
\hline Sex & & & \\
\hline Male & $0.2 \%^{\mathrm{p}=0.638}$ & $0.1 \%^{\mathrm{p}=0.831}$ & $0.6 \%^{\mathrm{p}=0.778}$ \\
\hline Female & $0.4 \%$ & $0.1 \%$ & $0.5 \%$ \\
\hline Race & $3.8 \%^{\mathrm{p}<0.001}$ & $0.4 \%^{\mathrm{p}=0.020}$ & $0.0 \%{ }^{\mathrm{p}=0.361}$ \\
\hline Caucasian & $0.2 \%$ & $0.1 \%$ & $0.7 \%$ \\
\hline Black & $0.0 \%$ & $0.2 \%$ & $0.0 \%$ \\
\hline Hispanic & $0.0 \%$ & $0.0 \%$ & $0.0 \%$ \\
\hline Asian & $0.4 \%$ & $<0.1 \%$ & $0.0 \%$ \\
\hline O/NR & & & \\
\hline
\end{tabular}

ACS - Acute chest syndrome, O/NR - other/not recorded during hospitalization, statistical analysis exponents compare death rates by cohort - i.e. \% of males vs. females that died during hospitalization, percentages represent proportions for a given cohort

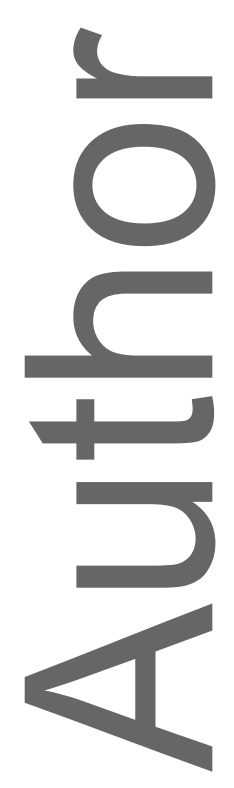

This article is protected by copyright. All rights reserved. 